\title{
Validation of Minnesota acute graft-versus-host disease Risk Score
}

\author{
Margaret L. MacMillan, ${ }^{1,2}$ Todd E. DeFor,,${ }^{1,3}$ Shernan G. Holtan, ${ }^{1,4}$ \\ Armin Rashidi, ${ }^{1,4}$ Bruce R. Blazar ${ }^{1,2}$ and Daniel J. Weisdorf ${ }^{1,4}$ \\ ${ }^{1}$ Blood and Marrow Transplant Program, University of Minnesota Medical School, \\ Minneapolis, MN; ${ }^{2}$ Department of Pediatrics, University of Minnesota Medical School, \\ Minneapolis, MN; ${ }^{3}$ Biostatistics and Informatics Core, Masonic Cancer Center, University \\ of Minnesota Medical School, Minneapolis, MN and ${ }^{4}$ Department of Medicine, University \\ of Minnesota Medical School, Minneapolis, MN, USA
}

\section{ABSTRACT}

U sing multicenter data, we developed a novel acute graft-versus-host disease Risk Score which more accurately predicts response to steroid treatment, survival and transplant related mortality than other published risk scores based upon clinical grading criteria. ${ }^{1}$ To validate this Risk Score in a contemporary cohort, we examined 355 recent University of Minnesota patients (2007-2016) diagnosed with acute graftversus-host disease and treated with prednisone $60 \mathrm{mg} / \mathrm{m}^{2} /$ day for 14 days, followed by an 8-week taper. Overall response [complete response + partial response] was higher in the 276 standard risk versus 79 high risk graft-versus-host disease patients at day $14(71 \%$ versus $56 \%, P<0.01)$, day $28(74 \%$ versus $59 \%, P=0.02)$ and day $56(68 \%$ versus $49 \%, P<0.01)$ after steroid initiation. Day 28 response did not differ by the initial graft-versus-host disease grade. In multiple regression analysis, patients with high risk graft-versushost disease were less likely to respond at day 28 (odds ratio $0.5,95 \% \mathrm{CI}$ $0.3-0.9, P<0.01)$ and had higher risks of 2 year transplant related mortality (Hazard Ratio 1.8, 95\% CI, 1.0-2.1, $P=0.03$ ) and overall mortality (Hazard Ratio 1.7, 95\% CI, 1.2-2.4, $P<0.01$ ) than patients with a standard risk graftversus-host disease. This analysis confirms the Minnesota graft-versus-host disease Risk Score as a valuable bedside tool to define risk in patients with acute graft-versus-host disease. A tailored approach to upfront acute graftversus-host disease therapy based upon the Minnesota Risk Score may improve outcomes and facilitate testing of novel treatments in these patients.

\section{Introduction}

Acute graft-versus-host disease (GvHD) remains a major cause of morbidity and mortality after allogeneic hematopoietic cell transplantation (HCT). ${ }^{2}$ Immediate, real time risk determination at diagnosis may facilitate initiation of more appropriate and potentially effective upfront therapy. In 2015, we developed a novel GvHD Risk Score based on the number of organs involved and severity of GvHD at the onset of systemic steroid treatment in 1723 patients from four centers and the Blood and Marrow Transplant Clinical Trials Network (BMT CTN) treated from 1990-2007. ${ }^{1}$ Using clinical groupings, descriptive statistics and recursive partitioning, we identified poorly responsive, high-risk (HR) acute GvHD defined by the number of involved organs and organ stage, thus determining the severity of GvHD at onset. HR-GvHD is defined as either skin stage 4; lower gastrointestinal (GI) stage 3-4 or liver stage 3-4; or skin stage 3+ and either lower GI 2-4 or liver stage 24 GvHD. Standard risk (SR)-GvHD includes single organ involvement (either stage 1-3 skin or stage 1-2 GI) or 2 organ involvement (either stage 1-3 skin plus stage I GI; or stage 1-3 skin plus stage 1-4 liver). We designed a free web-based program to easily determine the GvHD risk group for a given patient using our refined Risk Score, available at: https://z.umn.edu/MNAcuteGVHDRiskScore. Patients with HRGvHD were three times less likely to respond to steroid therapy and had a $>2$ fold increased risk of overall mortality and transplant-related mortality (TRM) than patients in the SR-GvHD group.
Ferrata Storti Foundation

\section{Correspondence: \\ MARGARET L. MACMILLAN macmi002@umn.edu}

Received: March 29, 2019.

Accepted: Juy 12, 2019

Pre-published: Juy 18, 2019.

doi:10.3324/haematol.2019.220970

Check the online version for the most updated information on this article, online supplements, and information on authorship \& disclosures: www.haematologica.org/content/105/2/519

\section{(C)2020 Ferrata Storti Foundation}

Material published in Haematologica is covered by copyright. All rights are reserved to the Ferrata Storti Foundation. Use of published material is allowed under the following terms and conditions:

https://creativecommons.org/licenses/by-nc/4.0/legalcode. Copies of published material are allowed for personal or internal use. Sharing published material for non-commercial purposes is subject to the following conditions:

https://creativecommons.org/licenses/by-nc/4.0/legalcode, sect. 3. Reproducing and sharing published material for commercial purposes is not allowed without permission in writing from the publisher. 


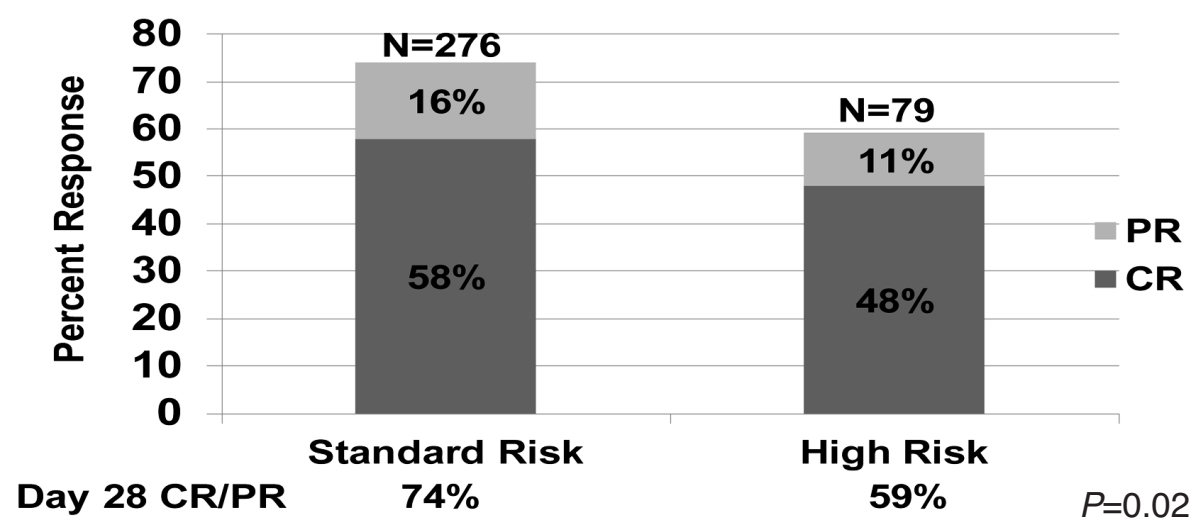

\begin{tabular}{|l|c|c|l|}
\hline & Standard Risk & High Risk & $P$ \\
\hline Day 14 CR/PR & $\mathbf{7 1 \%}$ & $56 \%$ & $<0.01$ \\
\hline Day 56 CR/PR & $68 \%$ & $49 \%$ & $<0.01$ \\
\hline
\end{tabular}

Figure 1. Response by Minnesota GvHD Risk Score.

As measured by the net reclassification index, the Minnesota GvHD Risk Score improves both the true-positive and false-positive rates and is a better predictor of response to upfront steroid therapy, survival and TRM than other published GvHD Risk Scores based upon clinical grading criteria. ${ }^{1}$ Our previous analysis revealed that this GvHD Risk Score would reclassify 83\% patients graded by the Center for International Blood and Marrow Transplant Research (CIBMTR) grading system ${ }^{3}$ and $27 \%$ if the Minnesota GvHD grading system ${ }^{4,5}$ were used allowing for more appropriate, risk stratified therapy at initial GvHD diagnosis. ${ }^{3-6}$

To validate this Minnesota GvHD Risk Score in a contemporary cohort with greater variety of conditioning regimens and donor grafts, we examined an independent cohort of 355 patients diagnosed with acute GvHD who were treated with systemic steroids as initial therapy at the University of Minnesota.

\section{Methods}

Between December 2007 and December 2016, 355 first allogeneic HCT patients developed grade I-IV acute GvHD and were treated with prednisone $60 \mathrm{mg} / \mathrm{m}^{2} /$ day per os (PO) (or methylprednisolone $48 \mathrm{mg} / \mathrm{m}^{2} /$ day intravenously (IV)) as initial therapy and are included in this analysis. Patients with grade I GvHD not treated with systemic therapy were excluded from this analysis. All HCT protocols were reviewed and approved by the Masonic Cancer Center Protocol Review Committee and the Institutional Review Board at the University of Minnesota.

\section{Patient and transplant characteristics}

Patient and transplant characteristics are shown in Table 1 for our new cohort of 355 patients as well as our old cohort of 1723 patients for comparison. The date of transplant did not overlap between the two groups. The median patient age was similar being 49 years (range, $0.2-75$ ) and 40 years (range $0.2-76$ ). In each cohort, $62 \%$ were males and the majority had a malignant disease.
In both groups approximately $1 / 3$ of patients received a human leukocyte antigen (HLA)-matched sibling bone marrow (BM) or peripheral blood stem cell (PBSC) donor graft. In our new cohort, there were fewer HLA matched or mismatched unrelated donor (URD) grafts used. A much greater proportion of patients received an umbilical cord blood (UCB) graft; now $55 \%$ compared to only $15 \%$ previously. Details of the preparative therapy, GvHD prophylaxis and supportive therapies have been previously reported. 7-10 In the new cohort, $50 \%$ patients received reduced intensity conditioning (RIC) compared to only $26 \%$ patients previously. In our new cohort, GvHD prophylaxis consisted of cyclosporine A (CSA) or tacrolimus based therapy in $92 \%$ of patients, ex vivo T-cell depletion in 1\% of patients, and sirolimus plus mycophenolate mofetil (MMF) in $7 \%$ of patients.

\section{GvHD therapy and measurement of response to prednisone}

All patients were to receive daily, thrice divided doses of prednisone $60 \mathrm{mg} / \mathrm{m}^{2} /$ day orally (or methylprednisolone IV equivalent, $48 \mathrm{mg} / \mathrm{m}^{2}$ ) for seven consecutive days, followed by daily prednisone for seven days as initial therapy for acute GvHD. Patients were maintained on therapeutic levels of CSA, tacrolimus or sirolimus. Additionally, patients with skin acute GvHD were treated with topical $0.1 \%$ triamcinolone cream or $1 \%$ hydrocortisone cream (for facial rash) three times daily. If a response to prednisone was observed, patients continued therapy with oral prednisone 60 $\mathrm{mg} / \mathrm{m}^{2} /$ day through day 14 and then commenced a taper of steroids over eight weeks. ${ }^{11,12}$ Response to therapy was evaluated by the attending physician and prospectively recorded weekly in the University of Minnesota BMT Database by determining the GvHD clinical stage score for each time point $( \pm 3$ days $) .{ }^{13}$ Additional detail of GvHD data collection and scoring, supportive care and statistical analyses are detailed in the Online Supplementary Methods section.

\section{Results}

For the entire cohort, the median time from HCT to initiation of steroid therapy was 37 days (range 10-170, 
interquartile range 26-57). All patients had $\geq 6$ months follow-up after steroid initiation (median 3.2 years, range 0.5-9 years).

The initial organ stage of GvHD at onset of steroid treatment is shown in Table 2. Initial GvHD organ involvement was skin only (45\%), upper gastrointestinal (GI) only (5\%), upper and/or lower GI only (33\%), liver only $(1 \%)$ or multi-organ $(21 \%)$. At onset of steroid therapy, $11 \%$ had grade I GvHD, 53\% patients had grade II GvHD, $30 \%$ had grade III GvHD and 6\% had grade IV GvHD. Of the 355 patients, 79 (22\%) had Minnesota HR GvHD and $276(78 \%)$ had Minnesota SR GvHD. The median onset of GvHD treatment in SR patients was 37 days [range, 10170 , interquartile range (IOR), 26.5-57] and 39 days (range, 13-156, IOR, 23-57) in HR patients.

Overall response $(\mathrm{CR}+\mathrm{PR})$ at day 28 was observed in 250 of 355 patients [70\%: 95\% confidence interval (CI), $65-75 \%$ ]. CR was observed in 199 patients [56\%: 95\% CI, $51-61 \%$ ) and PR in 51 patients [14\%: 95\% CI, 11-18\%). CR/PR was significantly higher in the 276 SR versus $79 \mathrm{HR}$ GvHD patients at day $14(71 \%$ versus $56 \%, P<0.01)$, day $28(74 \%$ versus $59 \%, P=0.02$; Figure 1$)$ and day $56(68 \%$ versus $49 \%, P<0.01)$ after steroid initiation. Day $28 \mathrm{CR} / \mathrm{PR}$ did not differ by initial GvHD grade being $64 \%, 77 \%$, $65 \%$ and $50 \%$ for grade I, II, III and IV $(P=0.07)$, noting that Grade I, II and III had similar day 28 CR/PR. Evaluating high risk for each index as classified by Minnesota HR GvHD, grades III/IV for the Minnesota GvHD grading system, and grades C/D for the CIBMTR grading system, the positive predictive value for no response was $41 \%$ (95\% CI, 30-52\%), 38\% (95\% CI, 29 $47 \%$ ) and $33 \%$ (95\% CI, $27-40 \%$ ), respectively.

TRM at six months was significantly higher in the HR (34\%: 95\% CI, $23-45 \%$ ) versus SR patients $[21 \%$ : $95 \% \mathrm{CI}$, $16-25 \% ; P<0.01)$ as shown in Figure 2. TRM at six months was also higher in patients with no response to steroids at day 28 (44\%: 95\% CI, 32-55\%) versus those who achieved a PR [16\%: 95\% CI, 6-27\%) or CR (13\%: 95\% CI, 9-18\%; $P<0.01)$ as shown in Figure 3.

In multiple regression analysis, adjusting for clinically significant variables, the odds of day $28 \mathrm{CR} / \mathrm{PR}$ were lower in HR versus SR GvHD patients [odds ratio (OR) 0.5, $95 \% \mathrm{CI}, 0.3-0.9, P=0.01)$. Donor type was the only other factor significantly associated with response. HLA matched URD BM/PBSC recipients were less likely to achieve a CR/PR at day 28 (OR 0.3, 95\% CI, 0.2-0.7, $P<0.01)$ versus $\mathrm{HLA}$ sibling donor $\mathrm{BM} / \mathrm{PBSC}$ recipients, whereas single UCB graft recipients were 3.6 times as likely to respond (OR 3.6, 95\% CI,1.4-9.2, P=0.01) and double UCB recipients 1.9 twice as likely to respond (OR 1.9, $95 \% \mathrm{CI}, 1.0-3.5, P=0.04$ ) as shown in Table 3 . There were no statistically significant interactions in donor, graft or other variables with response.

We also performed a logistic regression analysis of day $28 \mathrm{CR} / \mathrm{PR}$ only in the $159 \mathrm{BM} / \mathrm{PBSC}$ (non-UCB recipients). Compared to Minnesota SR GvHD patients, the HR group had OR of 0.2 of achieving a day 28 CR and 0.2 of achieving CR/PR (both $P<0.01$ ). The Minnesota GvHD Risk Score also predicted CR/PR in the small number of patients with non-malignant disease as well (data not shown).

In multiple regression analysis, factors statistically significantly associated with greater TRM through 2 years included HR GvHD (Hazard Ratio (HzR) 1.8, 95\% CI, 1.12.7, $P=0.01$ ), and matched URD BM/PBSC recipients (HzR
2.0, 95\% CI, 1.1-3.5, $P=0.02)$. Lower TRM was associated with patients $18-35$ years of age $(\mathrm{HzR} 0.6,95 \% \mathrm{CI}, 0.3-$ 1.1, $P=0.02$ ), single UCB (HzR 0.4, 95\% CI, 0.2-1.0, $\mathrm{p}=0.04)$ and early onset $(<28$ days from HCT) GvHD (HzR 0.92 , 95\% CI, 0.87-0.97, $P=0.05)$. Similarly, mortality through 2 years was higher in HR GvHD (HzR 1.7, 95\% CI, 1.2-2.4, $P<0.01)$, matched URD BM/PBSC recipients (HzR 1.8, 95\% CI,1.1-3.0, $P=0.01$ ) and HCT-comorbidity

Table 1. Patient and transplant characteristics.

\begin{tabular}{lcc} 
Characteristic & New cohort & Old cohort \\
Number of patients & 355 & 1723 \\
Year of transplant & & \\
$1990-2000$ & & $1142(67 \%)$ \\
$2001-2007$ & & \\
$2007-2010$ & $112(32 \%)$ & \\
$2011-2016$ & $243(68 \%)$ & \\
\hline
\end{tabular}

Age, years

\begin{tabular}{lll} 
Median (range) & $49(<1-75)$ & $40(<1-76)$ \\
Gender: male & $221(62 \%)$ & $1067(62 \%)$ \\
\hline
\end{tabular}

Disease

Acute leukemia $\quad 196(55 \%) \quad 741(43 \%)$

CML $13(4 \%) \quad 217(13 \%)$

CLL/other leukemia $\quad 20(6 \%) \quad 73(4 \%)$

MDS/MPN $\quad 57(16 \%) \quad 194(11 \%)$

HL/NHL $20(6 \%) \quad 236(14 \%)$

Other malignancies $\quad 10(3 \%) \quad 69(4 \%)$

Non-malignant $\quad 39(11 \%) \quad 193(11 \%)$

Donor Type

HLA identical sibling $\quad 101(28 \%) \quad 598(35 \%)$

1 antigen mismatched sibling $\quad 2(1 \%) \quad 73(4 \%)$

HLA matched unrelated $\quad 49(14 \%) \quad 626(36 \%)$

1 antigen mismatched unrelated $\quad 8(2 \%) \quad 164(10 \%)$

Umbilical cord blood $\quad 195(55 \%) \quad 262(15 \%)$

Conditioning

Myeloablative $\quad 178(50 \%) \quad 37(47 \%)$

Reduced Intensity $\quad 177(50 \%) \quad 42(53 \%)$

Initial GvHD Grade

\begin{tabular}{lcc} 
I & $39(11 \%)$ & $426(25 \%)$ \\
II & $188(53 \%)$ & $953(55 \%)$ \\
III & $108(30 \%)$ & $311(18 \%)$ \\
IV & $20(6 \%)$ & $33(2 \%)$ \\
\hline
\end{tabular}

Organ involvement

Multi-organ $\quad 76(21 \%) \quad 556(32 \%)$

Skin only $\quad 158(45 \%) \quad 910(53 \%)$

Liver Only $2(1 \%) \quad 23(1 \%)$

Lower GI +/- upper GI $\quad 118(33 \%) \quad 346(20 \%)$

Upper GI only $\quad 19(5 \%) \quad 111(6 \%)$

Days from transplant to initial steroids

Median (range) $37(10-170) \quad 30(2-178)$

Follow-up (years)

Median (range)

3.2 years $(0.5-9) \quad 4.9$ years $(0.3-17.7)$

CML: chronic myelogenous leukemia; CLL: chronic lymphocytic leukemia; MDS. myelodysplastic syndrome; MPN: myeloproliferative neoplasm; HL: Hodgkin lymphoma; NHL: Non-Hodgkin lymphoma. 


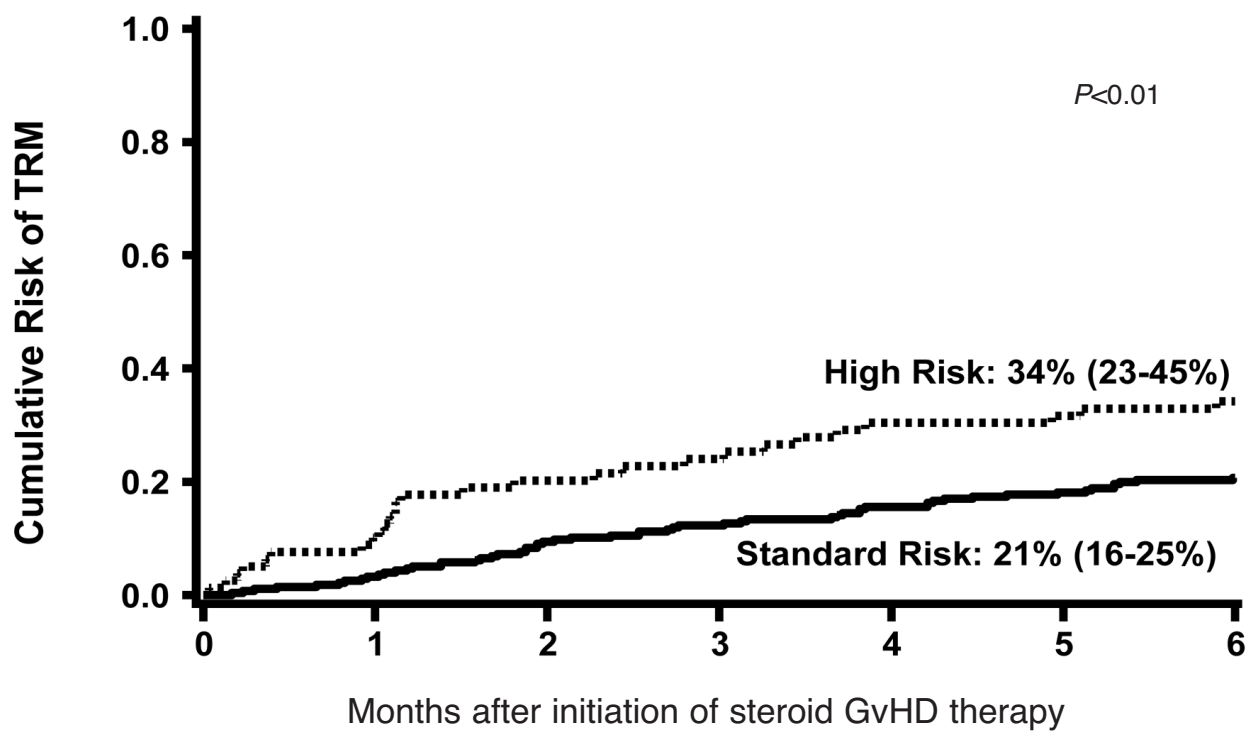

Figure 2. Cumulative incidence of TRM at 6 months after onset of steroid therapy by Minnesota GvHD Risk Score.

Table 2. GvHD organ stage at onset of steroid treatment.

\begin{tabular}{lccccc} 
Organ Stage & $\mathbf{0}$ & $\mathbf{1}$ & $\mathbf{2}$ & $\mathbf{3}$ & $\mathbf{4}$ \\
Skin & $121(34 \%)$ & $26(7 \%)$ & $52(15 \%)$ & $150(42 \%)$ & $6(2 \%)$ \\
Liver & $343(97 \%)$ & $7(2 \%)$ & $2(1 \%)$ & $2(1 \%)$ & $1(<1 \%)$ \\
\hline Lower GI & $200(56 \%)$ & $37(10 \%)$ & $56(16 \%)$ & $48(14 \%)$ & $14(4 \%)$ \\
Upper GI & $232(65 \%)$ & $123(35 \%)$ & & & \\
\hline
\end{tabular}

index (CI) score $\geq 3$ (HzR 1.7, 95\% CI,1.2-2.5, $P<0.01)$. There was a trend toward lower mortality in early onset GvHD (HzR 0.71, 95\% CI, 0.50-1.01, P=0.06). There were no statistically significant interactions with other covariates.

Two years after the initiation of the steroid therapy, 92 patients had developed chronic GvHD for a cumulative incidence of $26 \%$ (95\% CI $21-31 \%$ ). No differences in the incidence of chronic GvHD were observed in those with SR or HR acute GvHD (28\% verus $20 \%, P=0.54)$. Risks of chronic GvHD, however, were significantly lower in UCB recipients (HzR 0.6, 95\% CI, 0.5-0.9, $P=0.01$ ) and in early onset GvHD (HzR 0.95, 95\% CI, 0.92-0.98, $P<0.01$ ), but were higher in patients greater than 18 years of age $((\mathrm{HzR}$ $>2.8), P \leq 0.01$ ).

\section{Discussion}

We previously demonstrated that our refined multicenter Minnesota GvHD Risk Score, based upon the initial GvHD stage, serves as a better predictor of response and survival than either our previously published GVHD Risk Score based upon the initial GvHD grade, or the reported Minnesota or CIBMTR GvHD grading systems. ${ }^{14}$ To validate this refined Minnesota GvHD Risk Score, we examined a new, contemporary cohort of patients with acute GvHD treated at the University of Minnesota. This new cohort had a greater proportion of patients receiving RIC and more UCB recipients. Our results confirm that the Minnesota GvHD Risk Score, based upon the initial GvHD stage, is a valuable and immediately available bedside tool to define the risk in patients with acute GvHD. It also predicts the outcomes of response, survival and TRM better than other published GvHD Risk Scores determined by clinical grading criteria. These data suggest that a tailored approach to upfront GvHD therapy based upon this Minnesota acute GvHD Risk Score and other risk factors should be considered in order to improve outcomes and to plan novel treatment studies in patients with acute GvHD.

In 1974, the Glucksberg grading system was developed by examining the clinical severity of acute GvHD in 43 adult patients who received matched sibling donor (MSD) transplants after myeloablative conditioning from 1969-1973. ${ }^{15}$ This grading system was later modified, but in all iterations, grade III-IV acute GvHD was considered high risk. 4,12,16 In 1997, the CIBMTR grading system was developed from 2129 adult who received MSD transplants after myeloablative conditioning from 1986-1992, and patients with grades $\mathrm{C}$ and $\mathrm{D}$ are deemed high risk based upon subsequent survival, yet GvHD treatment response was not examined. ${ }^{3}$ However, clinical observations suggest there are some patients with grade III GvHD who do well while some patients with grade II GvHD fare poorly.

We first attempted to better identify HR acute GvHD at diagnosis by examining the outcomes of 864 patients at 
Table 3. Factors associated with day $28 \mathrm{CR} / \mathrm{PR}$, mortality and TRM: multiple regression analyses.

\begin{tabular}{|c|c|c|c|c|c|c|c|}
\hline Factors & $\mathbf{N}$ & $\begin{array}{c}\text { Odds Ratio of Day } \\
28 \mathrm{CR} / \mathrm{PR} \\
\text { (95\% CI) }\end{array}$ & $P$ & $\begin{array}{l}\text { Hazard Ratio of } 2 \\
\text { year Mortality } \\
\text { (95\% Cl) }\end{array}$ & $P$ & $\begin{array}{c}\text { Hazard Ratio of } 2 \\
\text { year TRM } \\
\text { (95\% CI) }\end{array}$ & $P$ \\
\hline Age & & & NS & & NS & & \\
\hline$<18^{*}$ & 65 & 1.0 & & 1.0 & & 1.0 & \\
\hline $18-35^{* *}$ & 50 & $2.2(0.8-6.0)$ & & $0.7(0.4-1.3)$ & & $0.6(0.3-1.1)$ & 0.09 \\
\hline $36-59$ & 151 & $1.2(0.5-2.5)$ & & $0.8(0.5-1.3)$ & & $0.5(0.3-0.9)$ & 0.02 \\
\hline $60+$ & 89 & $1.1(0.5-2.5)$ & & $1.1(0.6-2.0)$ & & $0.9(0.5-1.5)$ & 0.59 \\
\hline HCT-CI & & & NS & & & & NS \\
\hline $0^{*}$ & 172 & 1.0 & & 1.0 & & 1.0 & \\
\hline $1-2$ & 88 & $1.0(0.5-1.8)$ & & $0.9(0.6-1.4)$ & 0.66 & $0.9(0.5-1.5)$ & \\
\hline $3+$ & 95 & $1.2(0.6-2.1)$ & & $1.7(1.2-2.5)$ & $<0.01$ & $1.5(1.0-2.3)$ & \\
\hline \multicolumn{8}{|l|}{ Donor Type } \\
\hline Sibling* & 103 & 1.0 & & 1.0 & & 1.0 & \\
\hline Matched URD & 49 & $0.3(0.2-0.7)$ & $<0.01$ & $1.8(1.1-3.0)$ & 0.02 & $2.0(1.1-3.5)$ & 0.02 \\
\hline Mismatched URD & 8 & $1.9(0.3-10.4)$ & 0.48 & $1.0(0.4-3.0)$ & 0.95 & $1.0(0.3-3.4)$ & 0.98 \\
\hline Single UCB & 54 & $3.6(1.4-9.2)$ & 0.01 & $0.8(0.4-1.4)$ & 0.41 & $0.4(0.2-1.0)$ & 0.04 \\
\hline Double UCB & 141 & $1.9(1.0-3.5)$ & 0.04 & $1.2(0.8-1.8)$ & 0.38 & $1.2(0.7-1.9)$ & 0.57 \\
\hline $\begin{array}{l}\text { Weeks from HCT to Initial Steroid Rx } \\
\text { Continuous (/week) }\end{array}$ & & $1.02(0.96-1.08)$ & NS & $0.71(0.50-1.01)$ & 0.06 & $0.92(0.87-0.97)$ & 0.05 \\
\hline \multicolumn{8}{|l|}{ GVHD Risk ${ }^{\dagger}$} \\
\hline Standard Risk* & 276 & 1.0 & & 1.0 & & 1.0 & \\
\hline High Risk & 79 & $0.5(0.3-0.9)$ & & $1.7(1.2-2.4)$ & $<0.01$ & $1.8(1.1-2.7)$ & 0.01 \\
\hline
\end{tabular}

Bold indicates statistical significance. *Reference group †Standard Risk: single organ involvement (stage 1-3 skin or stage 1-2 GI) or two organ involvement (stage 1-3 skin plus stage $1 \mathrm{GI}$; or stage 1-3 skin plus stage 1-4 liver). All other patients are High Risk.

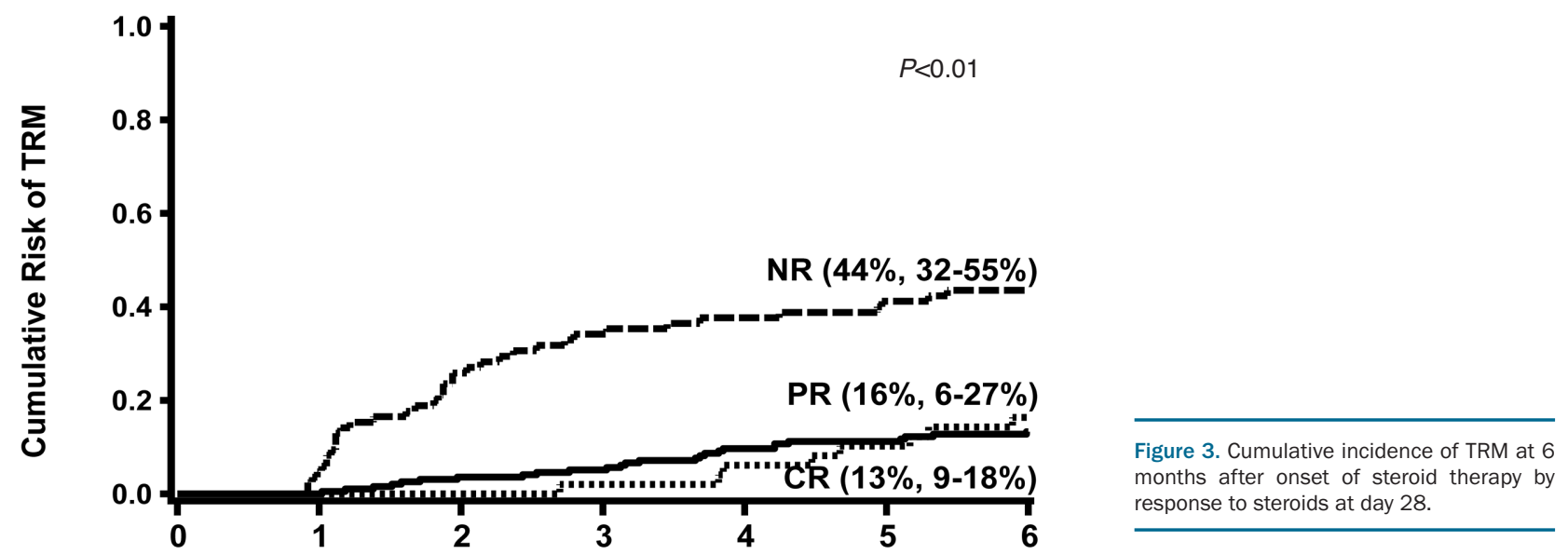

the University of Minnesota using a combined MinnesotaCIBMTR grading system devised by combining the initial GvHD grade as determined by the Minnesota and the CIBMTR grade. ${ }^{14}$ Patients with this HR GvHD were less likely to respond to steroid therapy and had a twofold increased risk of TRM compared to patients with SR GvHD. Thirty-three percent of the HR group in the Minnesota GvHD scoring system and 79\% of the HR in the CIBMTR system were reclassified as being SR. ${ }^{14}$

We tested this reported GvHD Risk Score, in a larger, multicenter and heterogeneous group of 1723 patients who received steroids as initial systemic therapy for acute GvHD. ${ }^{1}$ However, recognizing the variability in GvHD grading across sites, we then examined the details of initial GvHD organ stage combinations to determine whether stage groupings would better identify the patients at the highest risk than GvHD grading. We divided the 1723 patients into 67 categories by organ stage and, thus by the extent of GvHD involvement at onset. We collapsed these categories into 17 larger categories clustered as clinically similar cohorts with comparable $\mathrm{CR}+\mathrm{PR}$ at day 28 and evaluated these new GvHD staging categories for $\mathrm{CR}+\mathrm{PR}$, survival, and TRM. We found a clear demarcation between categories according to the $\mathrm{CR}+\mathrm{PR}$ rate at day 28 which also predicted the risks of 6 -month mortality and TRM. This allowed the division of the entire cohort 
into SR-GvHD and HR-GvHD groups to define our refined acute Minnesota GvHD Risk Score. ${ }^{1}$ As measured by the net reclassification index, our refined definition of GvHD improved both the true-positive and false-positive rates among our study population. ${ }^{1}$

In the current report including an independent contemporary cohort, even though with some differences in clinical characteristics, we now validate this Minnesota GvHD Risk Score, demonstrating prognostic utility that remains reliable in the new cohort. While biomarkers can associate with later outcomes, their assay takes time and requires measurement accuracy of a variety of reported indicators. Our clinical risk score should be the immediate and initial step in tailoring GvHD therapy, as it can be performed in real time.

The approach of stratification by this Minnesota GvHD Risk Score and later adjustment by biomarkers was used prospectively for the first time to establish eligibility criteria in the BMT CTN Protocol 1501, a randomized, phase II trial evaluating sirolimus versus prednisone in patients with SR GvHD. ${ }^{17}$ Of 122 patients classified by the Minnesota Risk Score at enrollment as having SR acute GvHD, only 4 patients (3\%) were deemed high risk by the biomarkers. Thus, we confirmed the accuracy of the Minnesota Risk Score using bedside GvHD risk assessment.

Further prospective trials using the Minnesota GvHD Risk Score along with informative and reliable biomarker results if available quickly are needed to better explore the GvHD risk. Additional studies using clinical classifiers supplemented with biomarkers may be of interest. A tailored approach to upfront acute GvHD therapy based upon the Minnesota GvHD Risk Score should be considered in order to improve outcomes in patients with acute GvHD. It may also improve risk stratification for future trials of initial GvHD therapy.

\section{Acknowledgments}

The authors thank the nurses, nurse coordinators, pharmacists and physicians who cared for these patients and their families. In addition, we gratefully acknowledge the nurses and research staff whose dedicated efforts facilitated the prospective collection of the GvHD data. The authors also thank the patients and the families for participating in the clinical research trials.

\section{Funding}

This study was supported in part by the National Institutes of Health, National Cancer Institute grant P01 CA065493-20.

\section{References}

1. MacMillan ML, Robin M, Harris AC, et al. A refined risk score for acute graft-versushost disease that predicts response to initial therapy, survival, and transplant-related mortality. Biol Blood Marrow Transplant. 2015;21(4):761-767.

2. Zeiser R, Blazar BR. Acute graft-versus-host disease - biologic process, prevention, and therapy. N Engl J Med. 2017; 377(22):21672179

3. Rowlings PA, Przepiorka D, Klein JP, et al. IBMTR Severity Index for grading acute graft-versus-host disease: retrospective comparison with Glucksberg grade. Br J Haematol. 1997;97(4):855-864.

4. Przepiorka D, Weisdorf D, Martin P, et al. 1994 Consensus Conference on acute GvHD grading. Bone Marrow Transplant. 1995:15(6):825-828.

5. Weisdorf DJ, Snover DC, Haake R, et al. Acute upper gastrointestinal graft-versushost disease: clinical significance and response to immunosuppressive therapy. Blood. 1990;76(3):624-629

6. Weisdorf $D$, Haake $R$, Blazar $B$, et al. Treatment of moderate/severe acute graftversus-host disease after allogeneic bone marrow transplantation: an analysis of clinical risk features and outcome. Blood. 1990;75(4):1024-1030.

7. MacMillan ML, DeFor TE, Weisdorf DJ. The best endpoint for acute GVHD treatment trials. Blood. 2010;115(26):5412-5417.

8. Miller WP, Rothman SM, Nascene D, et al. Outcomes after allogeneic hematopoietic cell transplantation for childhood cerebral adrenoleukodystrophy: the largest singleinstitution cohort report. Blood. 2011; 118(7):1971-1978.

9. Mallhi KK, Smith AR, DeFor TE, Lund TC, Orchard PJ, Miller WP. Allele-Level HLA Matching impacts key outcomes following umbilical cord blood transplantation for inherited metabolic disorders. Biol Blood Marrow Transplant. 2017;23(1):119-125.

10. MacMillan ML, DeFor TE, Young JA, et al. Alternative donor hematopoietic cell transplantation for Fanconi anemia. Blood. 2015; 125(24):3798-3804.

11. Hings IM, Filipovich AH, Miller WJ, et al. Prednisone therapy for acute graft-versushost disease: short- versus long-term treatment. A prospective randomized trial. Transplantation. 1993;56(3):577-580.

12. MacMillan ML, Weisdorf DJ, Wagner JE, et al. Response of 443 patients to steroids as primary therapy for acute graft-versus-host disease: comparison of grading systems. Biol Blood Marrow Transplant. 2002; 8(7):387-394

13. Hings IM, Severson R, Filipovich AH, et al. Treatment of moderate and severe acute GVHD after allogeneic bone marrow transplantation. Transplantation. 1994; 58(4):437-442.

14. MacMillan ML, DeFor TE, Weisdorf DJ What predicts high risk acute graft-versushost disease (GVHD) at onset?: identification of those at highest risk by a novel acute GVHD risk score. Br J Haematol. 2012;157(6):732-741.

15. Glucksberg H, Storb R, Fefer A, et al Clinical manifestations of graft-versus-host disease in human recipients of marrow from HL-A-matched sibling donors Transplantation. 1974;18(4):295-304

16. Thomas ED, Storb R, Clift RA, et al. Bonemarrow transplantation (second of two parts). N Engl J Med. 1975;292(17):895-902.

17. Pidala JA, Hamadani M, Dawson $P$, et al Sirolimus Vs. prednisone as initial systemic therapy for Minnesota standard risk (MN SR), Ann Arbor 1/2 acute graft-vs.-host disease (GVHD): primary results of the multicenter randomized phase II BMT CTN 1501 Trial. Vol. 25 (3), Supplement. Biol Blood Marrow Transplant. 2019:S50-S51. 